\title{
Brachytherapy: a dying art or missed opportunity?
}

\author{
Annette Haworth ${ }^{1,2}$
}

Published online: 10 March 2016

(c) Australasian College of Physical Scientists and Engineers in Medicine 2016

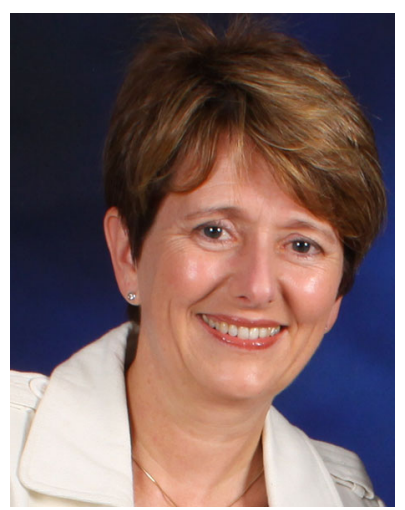

A couple of years ago I was asked to sit on an expert review committee to consider an overhaul of the brachytherapy module of the Australasian TEAP Clinical Training Guide. Considering the contents of the guide was the easy bit, working out how our junior physicists could achieve the required skills and competencies was something else. Before I tell you how we arrived at our recommendations, let me share with you some background information and my concerns for the future of brachytherapy.

Not all centres in Australia and New Zealand offer a brachytherapy service, and even those that do, the range of practices varies and caseloads are not high in all but a few centres. In fact, over recent years there has been an alarming decline in the utilisation rates of brachytherapy internationally [1-3]. The decline is alarming when we

Annette Haworth

annette.haworth@petermac.org

1 Department of Physical Sciences, Peter MacCallum Cancer Centre, Melbourne, VIC, Australia

2 The Sir Peter MacCallum Department of Oncology, University of Melbourne, Melbourne, VIC, Australia consider that there is compelling evidence that brachytherapy, in appropriately selected patients, is capable of accurately delivering a highly conformal dose of radiation to the tumour and lower doses to surrounding healthy tissue compared with external beam radiotherapy (EBRT). Despite this we seem to be losing referrals to our EBRT colleagues who claim that with exciting advances in technology, there are increasing opportunities for EBRT to safely deliver tightly conformal fields of radiation in a small number of fractions...something we've been doing in brachytherapy for many years! Furthermore, there are many studies that show brachytherapy is the most cost effective form of radiotherapy treatment for many cancers [4].

Take prostate cancer for example: Martin et al. reported a decline from $16.7 \%$ utilisation rate in the US for prostate brachytherapy in 2002, to $8 \%$ in 2010 [2]. This is despite clear evidence for superior biochemical control rates when used alone in low risk prostate cancer, or in combination with EBRT in higher risk cancers compared with surgery or EBRT alone [5]. The situation for treatments for cancer of the cervix is a little more disturbing. Han et al. noted a decline in the utilisation of brachytherapy for cervix cancer from $83 \%$ in 1988 to $58 \%$ in 2009 , noting a particular dip in the utilisation in 2003 which happened to coincide with the introduction of a healthcare rebate for intensity modulated radiotherapy (IMRT) in the US [1]. This is despite significantly higher rates of cause specific survival and overall survival in patients treated with brachytherapy. These concerns have similarly been reported by Thompson et al. when considering utilisation rates in the Australian setting, but also noting that treatment quality is also impacted by caseload, with centres treating less than 10 patients per year frequently providing treatments of "suboptimal quality" $[6,7]$. 
In reviewing the Australian Medicare data (http://www. medicareaustralia.gov.au/statistics/mbs_item.shtml) in the period 2010-2016, we can see that the number of gynaecological cancer cases in Australia has remained fairly stable (Fig. 1), however, in breaking the figures down by type of implant, the number of tandem and ovoid treatments (Medicare Benefits Schedule (MBS) item 15324) and vaginal vaults (MBS item 15316) has steadily increased, whereas the number of transperineal implants has more than halved, from 679 in 2010 to 314 in 2015. Low-dose-rate LDR prostates have similarly declined by around $50 \%$ (745 cases in 2010, 393 cases in 2015), but the biggest decline is in the utilisation of high-dose-rate (HDR) prostate treatments, declining from 313 cases in 2010 to just 125 cases in 2015 . The reasons for the decline are unclear though the decline in the utilisation rates for LDR brachytherapy could well be related to the recommendations of the Urological Society of Australia and New Zealand that advocates the use of active surveillance in men with low risk cancer, the cohort most suitable for LDR brachytherapy - a highly controversial recommendation.

In the case of prostate cancer, Petereit et al. suggested 6 reasons for the decline of brachytherapy utilisation in the US, these included: (1) an increase in the use of robotic prostatectomies (2) increase in the sophistication of EBRT (IMRT and image guided radiotherapy (IGRT)), stereotactic ablative body radiotherapy (SABR) and proton therapy (3) increase in the reimbursement for IMRT (4) negative press as the result of poor quality implants [8] (5) limited opportunities for training due to the reduced number of facilities offering brachytherapy (6) few physicians have brachytherapy experience and are therefore less likely to refer patients [3]. Whilst these reasons may apply in Australia and New Zealand to a greater or lesser extent, all require some consideration if we acknowledge the clear clinical and economic benefits. Most of the articles related

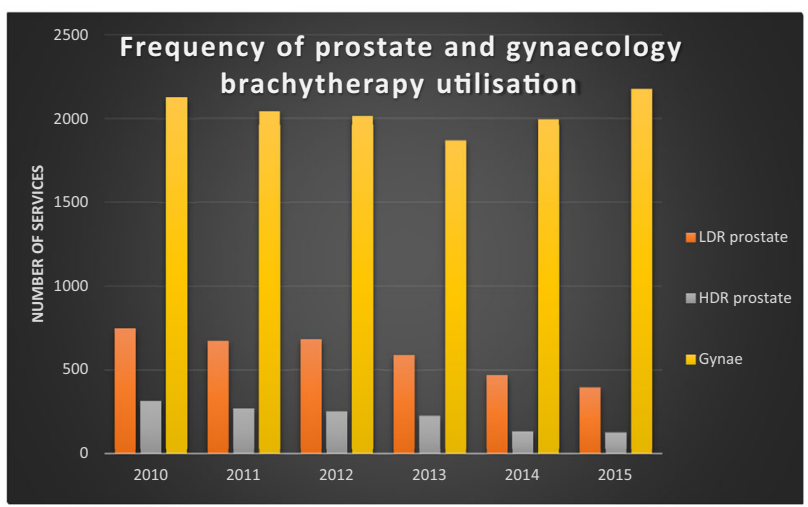

Fig. 1 Number of cases treated with brachytherapy in Australia with brachytherapy. Data source: http://www.medicareaustralia.gov.au/ statistics/mbs_item.shtml accessed February 2016, MBS item numbers: 15324, 15316, 15332 (HDR gynaecological (gynae) codes), 37227 (HDR prostate), 37220 (LDR prostate) to the decline in the utilisation of brachytherapy that I have discussed so far are directed to clinicians. But I think we as physicists have a role in promoting the use of brachytherapy. So, here is my list of more technically directed arguments for continuing to promote the use of brachytherapy:

\section{Dose conformity}

We have already looked at the clinical papers reporting excellent clinical outcomes. Not surprising when you consider that brachytherapy delivers the ultimate form of conformal radiotherapy with its ability to accurately deliver high doses of radiation to the target volume. Indeed Georg et al. [9] in a planning study of 10 patients with localised prostate cancer, compared the dose distributions using: volumetric modulated arc therapy, scanned proton therapy, scanned carbon-ion therapy, and LDR and HDR brachytherapy treatment of localized prostate cancer. This paper concluded brachytherapy techniques were clearly superior in terms of bladder wall, rectal wall, and normal tissue sparing. The lowest values were achieved with HDR, additionally achieving a 10 Gy sparing of the urethra when taking the radiobiological effectiveness of all treatments into account.

\section{Advanced imaging}

The improvements in clinical results for many tumour sites using EBRT have largely been a result of advanced imaging techniques available at the diagnostic, planning and treatment stages. Indeed Zelefsky et al. reported a $50 \%$ reduction in genito-urinary toxicity with the introduction of high dose IMRT and IGRT compared with nonIGRT techniques [10]. It would be fair to say that the brachytherapy community has been slow to embrace the advanced imaging opportunities available to us for treatment planning. If we consider treatment of advanced cervical cancer for example, van Dyk et al. in 2009 in a survey of 27 Australian and New Zealand centres, found only $15 \%$ were using MRI to guide treatment planning, and that planning was largely based on the Manchester system, relying on a geometric, rather than anatomical basis for the prescription [11, 12]. Prostate brachytherapy (LDR and HDR) could also benefit by introducing MRI into the treatment program due to the improved confidence in contouring the prostate in the presence of artefacts due to seeds [13] and catheters. Many argue that MRI is costly, but I would suggest that we have not yet fully costed MRI guided brachytherapy compared with either a full course of image guided EBRT or SABR. Furthermore, use of advanced imaging techniques also opens the possibility to 
move from whole gland therapy, to 'focal' or 'focussed' therapy which targets selected regions of the prostate for treatment, leaving the rest of the gland either untreated or receiving a lower dose of radiation offering the potential for reduced treatment related toxicity $[14,15]$.

\section{Development of specialised applicators}

Traditional methods of breast brachytherapy required the skills of a competent surgeon to carefully guide the catheters into a precise geometric array according to the Paris system [16]. Whilst implanting catheters this way is still practiced today, using dose optimisation tools in our treatment planning systems now allows some deviation from a perfect implant and hence not be so dependent on the skills of a surgeon. Additionally we are seeing an increase in the number of simple catheter systems such as the SAVI applicator (Cianna Medical, CA, USA) which promises a simpler, single entry device to be implanted whilst retaining the ability to conform the dose distribution to the target volume. For a full discussion on modern approaches to breast brachytherapy I refer you to the review article of Lee et al. [17].

\section{Accurate dose calculation models}

Brachytherapy has been the poor relation to EBRT when considering sophistication of dose calculation algorithms. EBRT is however, more demanding of such sophistication due to the long path lengths of the high energy radiation potentially passing through multiple heterogeneities. Within the high dose region of a brachytherapy target volume, we do not see quite the variation in tissue densities that have troubled the EBRT community. However, the time has come when we realise we can do better and now we are seeing the early commercial release of model based dosimetry calculation algorithms [18]. Strictly speaking these algorithms are not ready for clinical use as we must first fully understand the clinical implications, meaning the need for changes in dose prescriptions or dose constraints, to ensure we do not radically change the way we treat our patients.

\section{Treatment verification}

I'm sad to say that brachytherapy trails woefully behind EBRT where we have been using record and verification systems for many years, and in vivo dosimetry is not uncommon (indeed, mandatory in some countries). I'm proud to say that Australia is absolutely leading the way in this field with several groups working on methods to address this problem for brachytherapy [19-21]. This topic is now high in interest in the field of brachytherapy with a full day workshop organised in conjunction with the 2016 World Brachytherapy Congress (https://www.american brachytherapy.org/meetings/annual2016).

\section{Radiobiology}

It is often claimed that the advantages of SABR compared with EBRT are that SABR treatments deliver a greater combined dose of radiation in far fewer treatments. This is because the highly conformal SABR treatments spare healthy tissue overcoming the potentially harmful effects of the hypofractionated schedule. However, delivering high doses in short periods of time has been the basis of brachytherapy treatments since the beginning. Apart from maybe cranial stereotactic radiosurgery, there are no studies utilising SABR or any form of hypofractionated radiotherapy treatments with long treatment follow up data. Indeed Duchesne and Peters [22] for example, suggested the theoretical advantage of delivering high doses of radiation in a short time frame for prostate cancers, as the evidence for a low $\alpha / \beta$ ratio emerged. Fully understanding the radiobiological advantages of brachytherapy during the treatment planning process has yet to be fully realised and in fact biologically based dose optimisation is something my own research group has been working on for several years and we hope to eventually introduce into the clinic in the not too distant future [23].

\section{Advanced treatment approaches}

There are many more areas of research in the field of brachytherapy (and electronic brachytherapy) that I would like to discuss, but as they would take many more pages I will just share with you my own passion and that is to see the advantages of brachytherapy pushed to their ultimate. There is much interest in the literature in moving from standardised approaches for cancer treatments to a personalised approach [24]; indeed, my research team has been working on developing a personalised, biologically based approach to treating prostate cancer where the radiation dose is tailored to the specific characteristics of the tumour. In other words, only those bits of the prostate that need it receive high doses [25]. Our framework draws on a quantitative approach to MRI and can be applied to prostate LDR or HDR, a concept that could be expanded to other treatment sites. Whilst this is not the place to promote my work, it is, I believe just one example of many exciting opportunities to exploit the many advantages of brachytherapy. 


\section{Training}

So now I will complete this article by returning to my opening comments regarding the TEAP program, in particular the brachytherapy module. The expert committee that I referred to in the beginning agonised over the reality that (a) many registrars would struggle to achieve the same level of competency in brachytherapy as we would expect in linac based radiotherapy, particularly those receiving training in non-brachytherapy centres, (b) due to the low utilisation rates of brachytherapy, it is probably not necessary for all registrars to achieve the competency you would expect at Level 3. The expert committee therefore offered the recommendation that achieving only Level 2 competency should be mandatory and that achieving Level 3 should be encouraged, especially those working in high volume brachytherapy centres. We debated at length the concern that too few registrars would take up the opportunity to achieve Level 3, and also, how to manage graduates of the program that would later want to complete the Level 3 training requirements. It is fair to say we had no easy answers, however, we agreed that it should be the responsibility of all brachytherapy physicists to spread the word: brachytherapy is here to stay, many possibilities for expanding the role of brachytherapy exist and it's a challenging but incredibly rewarding field to work in. Despite the difficulties we had in coming to this conclusion, I think it was the right one. However, I would like to add that I don't think brachytherapy physics training can be taught in isolation. Brachytherapy training needs to be carried out in a multi-disciplinary environment. Brachytherapy requires good communication and team work to achieve good quality treatments and avoid the hazards of bad press [8].

Finally, within the title of this editorial I asked if brachytherapy is a dying art or missed opportunity. I hope that I have now convinced you that a lot of the "art" behind brachytherapy has been replaced by good science, and that indeed there are many opportunities to further that science. So, for those of you already doing brachytherapyplease keep reminding your colleagues that brachytherapy remains a cost effective and clinically proven form of treatment for many cancers. For those of you not doing brachytherapy, I encourage you to attend a training course or a brachytherapy session at the next conference to see what you are missing out on!

\section{Want to know more?}

If you would like to share my passion and those of other brachytherapy professionals, or, you just want to learn some brachytherapy (registrar or not), then I encourage you to look out for the Australasian Brachytherapy Clinical Workshops (http://www.abg.org.au). Alternatively there are internships offered through the American Brachytherapy Society (http://www.americanbrachytherapy.org/) and the excellent teaching schools run by ESTRO (http://www. estro.org/school).

\section{References}

1. Han K, Milosevic M, Fyles A, Pintilie M, Viswanathan AN (2013) Trends in the utilization of brachytherapy in cervical cancer in the United States. Int J Radiat Oncol Biol Phys 87(1):111-119

2. Martin JM, Handorf EA, Kutikov A, Uzzo RG, Bekelman JE, Horwitz EM et al (2014) The rise and fall of prostate brachytherapy: use of brachytherapy for the treatment of localized prostate cancer in the National Cancer Data Base. Cancer 120(14):2114-2121

3. Petereit DG, Frank SJ, Viswanathan AN, Erickson B, Eifel P, Nguyen PL et al (2015) Brachytherapy: where has it gone? J Clin Oncol 33(9):980-982

4. Durkee BY, Buyyounouski MK (2015) The case for prostate brachytherapy in the Affordable Care Act era. Int J Radiat Oncol Biol Phys 91(3):465-467

5. Grimm P, Billiet I, Bostwick D, Dicker AP, Frank S, Immerzeel J et al (2012) Comparative analysis of prostate-specific antigen free survival outcomes for patients with low, int. \& high risk prostate cancer treatment by radical therapy. BJU Int 109:22-29

6. Thompson SR, Delaney GP, Gabriel GS, Barton MB (2014) Patterns of care study of brachytherapy in New South Wales: cervical cancer treatment quality depends on caseload. J Contemp Brachytherapy 6(1):28-32

7. Thompson SR, Delaney GP, Gabriel GS, Izard MA, Hruby G, Jagavkar R et al (2015) Prostate brachytherapy in New South Wales: patterns of care study and impact of caseload on treatment quality. J Contemp Brachytherapy 6(4):344-349

8. Bogdanich W (2009) Failed procedures at the Philadelphia VA. New York Times, New York

9. Georg D, Hopfgartner J, Gora J, Kuess P, Kragl G, Berger D et al (2014) Dosimetric considerations to determine the optimal technique for localized prostate cancer among external photon, proton, or carbon-ion therapy and high-dose-rate or low-dose-rate brachytherapy. Int J Radiat Oncol Biol Phys 88(3):715-722

10. Zelefsky MJ, Kollmeier M, Cox B, Fidaleo A, Sperling D, Pei X et al (2012) Improved clinical outcomes with high-dose image guided radiotherapy compared with non-IGRT for the treatment of clinically localized prostate cancer. Int J Radiat Oncol Biol Phys 84(1):125-129

11. Haie-Meder C, Potter R, Van Limbergen E, Briot E, De Brabandere M, Dimopoulos J et al (2005) Recommendations from Gynaecological (GYN) GEC-ESTRO Working Group (I): concepts and terms in 3D image based 3D treatment planning in cervix cancer brachytherapy with emphasis on MRI assessment of GTV and CTV. Radiother Oncol 74(3):235-245

12. van Dyk S, Byram D, Bernshaw D (2010) Use of 3D imaging and awareness of GEC-ESTRO recommendations for cervix cancer brachytherapy throughout Australia and New Zealand. J Med Imaging Radiat Oncol 54(4):383-387

13. De Brabandere M, Al-Qaisieh B, De Wever L, Haustermans K, Kirisits C, Moerland MA et al (2013) CT- and MRI-based seed localization in postimplant evaluation after prostate brachytherapy. Brachytherapy 12(6):580-588 
14. Langley S, Ahmed HU, Al-Qaisieh B, Bostwick D, Dickinson L, Veiga FG et al (2012) Report of a consensus meeting on focal low dose rate brachytherapy for prostate cancer. BJU Int 109(Suppl 1):7-16

15. Mason J, Al-Qaisieh B, Bownes P, Thwaites D, Henry A (2014) Dosimetry modeling for focal high-dose-rate prostate brachytherapy. Brachytherapy 13(6):611-617

16. Pierquin B, Marinello G (2000) A practical manual of brachytherapy. Medical Physics Publishing Corporation, Madison, WI

17. Lee CD (2014) Recent developments and best practice in brachytherapy treatment planning. Br J Radiol 87(1041):2014 0146

18. Beaulieu L, Carlsson Tedgren A, Carrier JF, Davis SD, Mourtada F, Rivard MJ et al (2012) Report of the Task Group 186 on model-based dose calculation methods in brachytherapy beyond the TG-43 formalism: current status and recommendations for clinical implementation. Med Phys 39(10):6208-6236

19. Espinoza A, Beeksma B, Petasecca M, Fuduli I, Porumb C, Cutajar D et al (2013) The feasibility study and characterization of a two-dimensional diode array in "magic phantom" for high dose rate brachytherapy quality assurance. Med Phys 40(11): 111702
20. Smith RL, Taylor ML, McDermott LN, Haworth A, Millar JL, Franich RD (2013) Source position verification and dosimetry in HDR brachytherapy using an EPID. Med Phys 40(11):111706

21. Suchowerska N, Jackson M, Lambert J, Yin YB, Hruby G, McKenzie DR (2011) Clinical trials of a urethral dose measurement system in brachytherapy using scintillation detectors. Int $\mathbf{J}$ Radiat Oncol Biol Phys 79(2):609-615

22. Duchesne GM, Peters LJ (1999) What is the alpha/beta ratio for prostate cancer? Rationale for hypofractionated high-dose-rate brachytherapy. Int J Radiat Oncol Biol Phys 44(4):747-748

23. Haworth A, Mears C, Betts JM, Reynolds HM, Tack G, Leo K et al (2016) A radiobiology-based inverse treatment planning method for optimisation of permanent 1-125 prostate implants in focal brachytherapy. Phys Med Biol 61(1):430-444

24. Jaffray DA (2012) Image-guided radiotherapy: from current concept to future perspectives. Nat Rev Clin Oncol 9(12): 688-699

25. Haworth A, Williams S, Reynolds H, Waterhouse D, Duchesne GM, Bucci J et al (2013) Validation of a radiobiological model for low-dose-rate prostate boost focal therapy treatment planning. Brachytherapy 12(6):628-636 